\title{
Assessing the blood meal hosts of Culex quinquefasciatus and Aedes taeniorhynchus in Isla Santa Cruz, Galápagos
}

Samoa Asigau ${ }^{1,2^{*}+} \mathbb{D}$, Sawsan Salah ${ }^{1,2+}$ and Patricia G. Parker ${ }^{1,2,3+}$

\begin{abstract}
Background: Blood meal host selection by mosquito vectors is an important component in understanding disease dynamics of pathogens that threaten endemic fauna in isolated islands such as Galápagos. Research on the feeding behavior of mosquitoes can provide clues to the hosts and vectors involved in disease transmission. This information is particularly critical for endemic wildlife fauna in island systems that have evolved without resistance to novel diseases such as avian malaria. The aims of this study were to determine the blood-feeding patterns of two species of mosquitoes found in Galápagos and discuss how their feeding behavior may influence the transmission of pathogens such as avian malaria.

Methods: In the summer of 2015, we sampled two mosquito species (Aedes taeniorhynchus and Culex quinquefasciatus) across 18 different sites on Isla Santa Cruz, which is the second largest island in Galápagos and has the largest human population. We trapped mosquitoes using CDC light traps and CDC gravid traps and identified sources of blood meals for engorged mosquitoes by sequencing a portion of the vertebrate mitochondrial cytochrome $b$ gene.

Results: Out of 947 female mosquitoes captured, 320 were blood-fed, and PCR amplifications were successful for 301 of the blood meals. Results revealed that both Aedes taeniorhynchus and Culex quinquefasciatus feed from a variety of vertebrate taxa, numerically dominated by humans on Isla Santa Cruz.

Conclusions: The high proportion of mammalian blood meals could represent locally available and abundant hosts on Santa Cruz. However, host surveys and estimates of relative abundances of vertebrate species will need to accompany mosquito trapping studies on non-inhabited and inhabited islands in Galápagos to further validate this.
\end{abstract}

Keywords: Mosquito, Feeding patterns, Galápagos, Aedes, Culex, Santa Cruz

\section{Background}

Knowledge of blood-feeding patterns by mosquitoes can provide an insight into disease dynamics and help manage parasites that pose threats to endemic wildlife. Many insects such as mosquitoes require a blood meal to complete their gonotrophic cycle and can thereby transmit

\footnotetext{
*Correspondence: sasigau@gmail.com

†Samoa Asigau, Sawsan Salah and Patricia G. Parker contributed equally to this work

${ }^{1}$ Department of Biology, University of Missouri, St. Louis, One University Blvd., St. Louis, MO 63121, USA

Full list of author information is available at the end of the article
}

blood-borne pathogens that threaten the health of wildlife and humans [1-3]. Host preference by mosquitoes appears to be heritable $[4,5]$ but can also depend on ecological factors like host availability, host abundance, vector abundance, habitat and climate $[6,7]$. In addition, when hosts become rare or limited, disease vectors may disperse to new habitats and modify their feeding behavior to a more diverse range of hosts. This shift in feeding behavior by disease vectors may have serious implications for disease transmission and dynamics, especially in novel habitats. For instance, numerous endemic birds in Hawaii faced extinction from the co-introduction of avian malaria

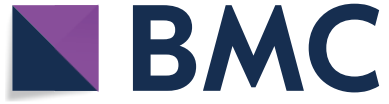

The Author(s) 2019. This article is licensed under a Creative Commons Attribution 4.0 International License, which permits use, sharing adaptation, distribution and reproduction in any medium or format, as long as you give appropriate credit to the original author(s) and the source, provide a link to the Creative Commons licence, and indicate if changes were made. The images or other third party material in this article are included in the article's Creative Commons licence, unless indicated otherwise in a credit line to the material. If material is not included in the article's Creative Commons licence and your intended use is not permitted by statutory regulation or exceeds the permitted use, you will need to obtain permission directly from the copyright holder. To view a copy of this licence, visit http://creativecommons.org/licenses/by/4.0/. The Creative Commons Public Domain Dedication waiver (http://creativecommons.org/ publicdomain/zero/1.0/) applies to the data made available in this article, unless otherwise stated in a credit line to the data. 
and avian pox, two virulent pathogens common to birds in continental areas. These parasites were likely carried to Hawaii from continents through migratory birds [8]. The mosquito vector Culex quinquefasciatus (Say, 1823) assisted in transmitting deadly pathogens from resistant migrants to naïve native birds, resulting in extinctions of many endemic Hawaiian bird species [1, 9].

The Galápagos Archipelago, located almost $1000 \mathrm{~km}$ from the west coast of mainland Ecuador, is similar to Hawaii in terms of its island ecosystem that is volcanic in origin. The islands are known for their high endemism that inspired Charles Darwin's theory of evolution by natural selection [10]. Given its iconic natural system, the archipelago's flora and fauna are well studied and human movements and impacts in the archipelago are at least partly controlled and monitored by the collective efforts of the Galápagos National Park and the Charles Darwin Research Station. Despite these efforts, the archipelago already hosts three mosquito vectors, $C x$. quinquefasciatus, Aedes aegypti (L.) and Aedes taeniorhynchus (Wiedemann, 1821). Estimated to have naturally arrived $\sim 200,000$ years ago [11], Ae. taeniorhynchus (or the black salt marsh mosquito) oviposits in brackish water [12]. In contrast, Ae. aegypti and Cx. quinquefasciatus require freshwater for oviposition and have been estimated to have established populations in the archipelago in 2001 and 1985, respectively [13, 14]. Aedes aegypti is highly anthropophilic and has been found in human-inhabited zones such as those on Santa Cruz and Isabela [13, 15].

The black salt marsh mosquito, Ae. taeniorhynchus, has been shown to have a strong preference for taking blood meals from reptiles and mammals over birds in mosquitoes sampled on uninhabited islands in the Galápagos archipelago [12]. However, it is unknown how its feeding preferences may change on human-inhabited islands. In addition, the blood meal host identities and possible preferences in Galápagos of a recent arrival, $C x$. quinquefasciatus, remain unknown. Our knowledge of host-parasite associations in Galápagos also remains fragmentary; therefore, studies of feeding behavior by mosquitoes may provide clues to the arthropod vectors involved in disease transmission.

The pathogens transmitted by mosquitoes include the haemosporidian blood parasites in the genus Plasmodium that cause avian malaria. Extensive sampling and molecular screening of endemic Galápagos penguin populations (Spheniscus mendiculus) revealed via PCR the presence of an avian parasite within the genus Plasmodium (lineage A) with infections detected in 3-9.4\% of sampled penguins per year $[16,17]$. However, the absence of gametocytes (stage of the parasite infective to arthropod vectors) within thin blood films prepared from infected penguins suggests parasitic abortive development, indicating that penguins could be dead-end hosts.
Three additional Plasmodium lineages (B, C, D) have since been discovered along with microscopic detection of a Plasmodium erythrocytic meront from a cactus finch (Geospiza scandens) and haemosporidian trophozoites from a vegetarian finch (Platyspiza crassirostris) [16]. Other arthropod-vectored pathogens known to infect Galápagos birds include several lineages of Haemoproteus (Order Haemosporida) [18-21], microfilarid nematodes [22] and avian poxvirus [23].

The transmission of pathogens in Galápagos may involve arthropod vectors such as mosquitoes. Therefore, it is important to understand the blood meal hosts of mosquitoes, which we aim to investigate for two mosquitoes common in Galápagos, Ae. taeniorhynchus and $C x$. quinquefasciatus, and discuss their role in transmitting important pathogens that threaten endemic wildlife in Galápagos.

\section{Methods}

\section{Study site}

This study was conducted on Santa Cruz Island, which is part of the Galápagos archipelago. Consisting of 13 major islands and 19 smaller islands, the archipelago is volcanic in origin and predominantly arid. The islands are known for their high endemism and low biodiversity with 530 species of fish and 111 other vertebrate species of mammals, birds and reptiles. There are 48 species of seabirds of which 19 are resident in Galápagos. Land birds constitute 29 resident species of which 22 are endemic and 4 are endemic to the level of subspecies. There are 25 mammal species consisting of two endemic species and 28 species of reptiles of which 19 are endemic [24].

Our study was conducted on Isla Santa Cruz between May 20th and August 3rd, 2015. Santa Cruz is the second largest island in Galápagos with a land area of $986 \mathrm{~km}^{2}$ and is one of four inhabited islands along with Isabela, Floreana and San Cristobal. The 2010 census recorded 15,000 inhabitants on Santa Cruz, making it the largest human population among the islands. This total represents $60 \%$ of the archipelago's human population [25] and nearly double the population of the whole archipelago since 1998. Likewise, the tourism industry has dramatically increased in the late 20th century, especially among inhabited islands. In 1969, approximately 2000 people visited the Galápagos Islands, which is a small fraction of the 180,000 people who visited in 2012 [26]. Compared to other islands, Santa Cruz hosts most of this human population and attracts tourists due to its developed infrastructure such as a hospital, schools, banks, shops, hotels and restaurants. Included in this infrastructure is a single $40 \mathrm{~km}$ paved road that extends from the north at Itabaca Channel, which is the entrance to Santa Cruz from the airstrip on adjacent Baltra Island, to the most southern 
tip at Puerto Ayora. Humans mainly inhabit the southern windward half of Santa Cruz since it provides ideal conditions for agriculture, and towns include Puerto Ayora, Miramar, Bellavista, Santa Rosa and Santa Martha.

\section{Mosquito survey}

We trapped mosquitoes across 18 sites along the main highway that stretches from the north at Itabaca Channel to the south at Puerto Ayora. Using the highway as a transect, we established 9 trapping stations spaced $5 \mathrm{~km}$ apart and set two trapping locations spaced at $300 \mathrm{~m}$ at each station to avoid edge effects, thus totaling 18 independent trapping sites (Fig. 1). At each site, we established a total of 4 points measuring $50 \mathrm{~m}$ apart and alternated 2 CDC light traps (Model 512 John Hock Company, Gainesville, USA) and 2 CDC gravid traps (Model 1712 John Hock Company) across these points. CDC light traps were baited with a $\mathrm{CO}_{2}$ emitting mixture consisting of $250 \mathrm{~g}$ sugar, $35 \mathrm{~g}$ yeast and 2.5 liters of water to attract host-seeking mosquitoes $[27,28]$ and gravid traps were baited with a hay-yeast-water infusion to attract ovipositing mosquitoes [29]. Traps were set within one hour of dusk and mosquitoes were collected in the morning the next day. Mosquitoes were immobilized with chloroform, sexed and identified to species level using morphological characters [30]. We classified female mosquitoes according to the Sella scale (1, unfed; $2-6$, partial to full blood meal; 7 , gravid) [31], dissected into head/thorax and abdomen regions using sterile techniques and stored individuals in Longmire's lysis buffer solution [32] in preparation for subsequent DNA extraction and blood meal analysis. For female mosquitoes that could not be dissected in the field due to feasibility and time constraints, we stored individual whole mosquitoes in $95 \%$ ethanol for subsequent dissections and DNA extraction in the Parker Laboratory at the University of Missouri, Saint Louis, USA. Mosquitoes preserved in ethanol could not be classed according to the Sella scale as the distinct digestive stages of female mosquitoes were often difficult to observe after months of preservation. Nonetheless, the sterile techniques applied to both field and laboratory dissected samples included cleaning hands before each dissection and utilizing a clean slide for every mosquito. Prior to dissecting each individual mosquito, we dipped dissection tools into $10 \%$ bleach, rinsed in distilled water, air-dried and applied heat to tools using a Bunsen burner. These techniques were strictly followed to avoid cross-contamination of specimen DNA.

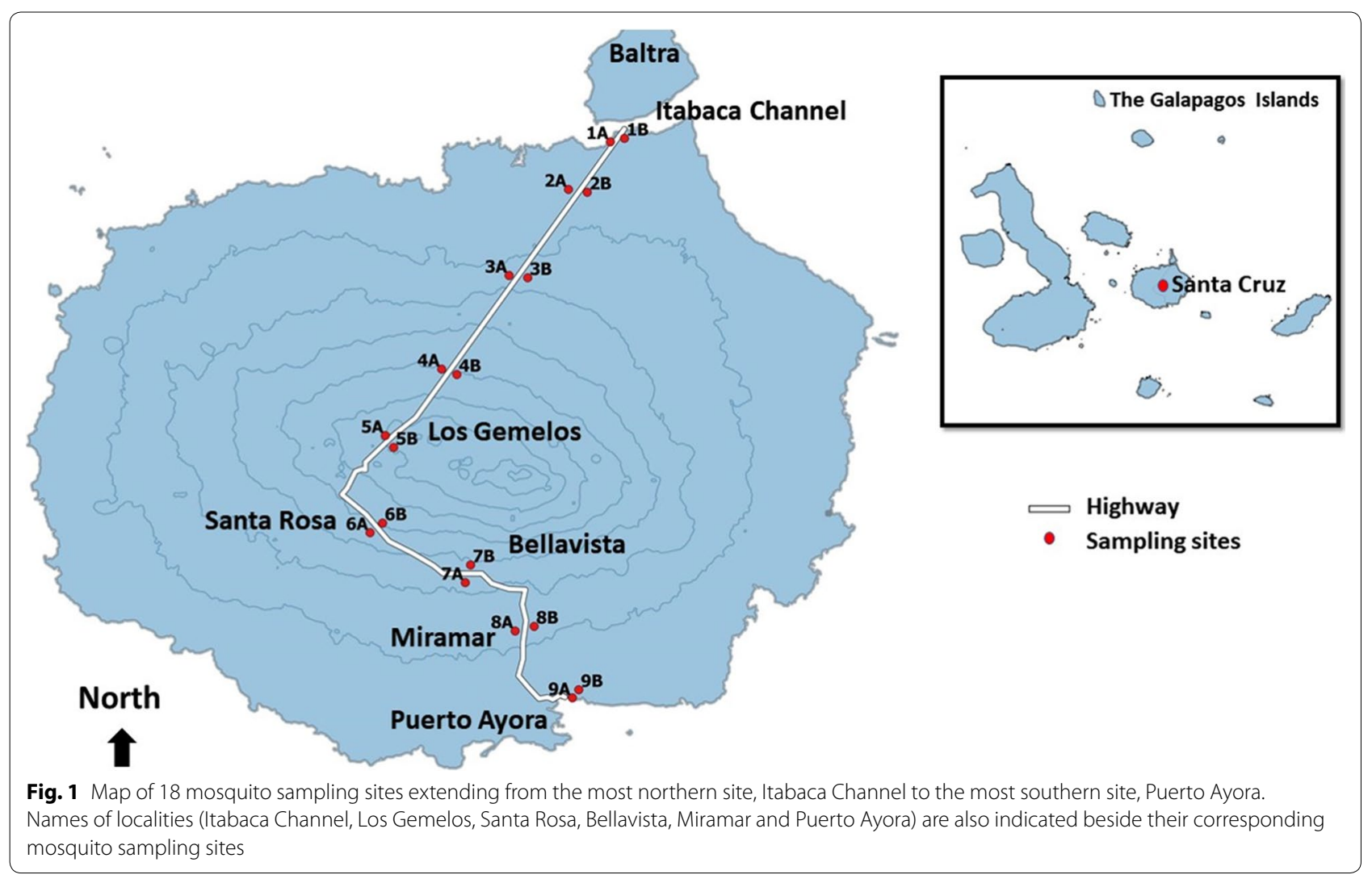




\section{Blood-meal analysis}

Genomic DNA from abdomens of female mosquitoes was extracted using Macherey-Nagel NucleoSpin ${ }^{\circledR}$ Tissue Kit (Macherey-Nagel, Bethleham, USA) according to manufacturer instructions. We used a universal BM primer set developed by Kocher et al. [33]; this primer set amplifies a fragment of $358 \mathrm{bp}$ of the vertebrate cytochrome $b(c y t b)$ gene (forward: $5^{\prime}$-CCC CTC AGA ATG ATA TTT GTC CTC A-3' and reverse $5^{\prime}$-CCA TCC AAC ATC TCA GCA TGA TGA AA- $3^{\prime}$ ) in assessing sources of mosquito blood meals via polymerase chain reaction (PCR). Negative controls were used (all reagents minus template DNA) and showed up as truly negative for all PCR reactions in this study. Positive controls included different taxa representing wildlife DNA samples from Galápagos species. Positive controls consisted of two individuals of marine iguanas (Amblyrhynchus cristatus), two species of birds (an introduced bird, the cattle egret Bubulcus ibis and an endemic bird, the large ground finch Geospiza magnirostris), and finally, two samples from a mammal (Homo sapiens). A Takara Taq PCR Kit (Takara Bio USA, Inc., Mountain View, USA) was used for all PCRs according to the manufacturer's recommendation. The PCR reaction contained $15.875 \mu \mathrm{l}$ of sterile distilled water, $2.5 \mu \mathrm{l}$ of $10 \times$ buffer (containing $100 \mathrm{mM}$ Tris- $\mathrm{HCl}$, $\mathrm{pH}$ 8.3, $500 \mathrm{mM} \mathrm{KCl}, 15 \mathrm{mM} \mathrm{MgCl}$ ), $2 \mu \mathrm{l}$ of dNTP mix (2.5 mM/l each), $1.5 \mu \mathrm{l}$ of $\mathrm{MgCl}_{2}(25 \mathrm{mM}), 1 \mu \mathrm{l}$ of each primer $(10 \mu \mathrm{mol} / \mathrm{l}), 0.125 \mu \mathrm{l}$ of Taq $(5 \mathrm{U} / \mu \mathrm{l})$ and $1 \mu \mathrm{l}$ of extracted DNA template in producing a total volume of $25 \mu \mathrm{l}$ [34]. Reactions were amplified to the PCR conditions following Hamer et al. [35]. Amplifications were assessed by gel electrophoresis using $1.5 \%$ agarose and positive PCR products were purified and sent to Eurofins Genomics LLC (Eurofins Genomics, Louisville, USA) for sequencing.

Sequencing results were subjected to BLAST search in GenBank and each chromatogram was inspected for sequence quality. Applying the rule of parsimony, our criteria involved analyzing sequencing chromatograms showing single peaks at each position as the source of blood meal for arthropod vectors. Mixed blood meals indicated by double or triple peaks on nucleotide chromatograms were removed from the analysis. Furthermore, samples that produced an ambiguous amplicon with no match or with low-quality peaks were re-run with a second reaction using an avian primer set (forward: 5'-GAC TGT GAC AAA ATC CCN TTC CA- $3^{\prime}$ and reverse: 5'-GGT CTT CAT CTY HGG YTT ACA AGA C-3') [34]. This primer set targets a 508-bp fragment size in the cytb gene under the reaction conditions described above [34, 35]. If amplicons failed to produce high-quality single peaks, we further subjected samples to a third reaction targeting $772 \mathrm{bp}$ in the mammalian cytb gene (primers-forward: 5'-CGA AGC TTG ATA TGA AAA ACC ATC GTT G-3' and reverse: 5'-TGT AGT TRT CWG GGT CHC CTA-3') [34]. Reactions also followed the same conditions described above. Samples that produced single peaks in any of the three reactions with a satisfactory match of $98-100 \%$ to sequences in GenBank were accepted as the source of origin for mosquito blood meals.

\section{Results \\ Mosquito survey}

A total of 1011 mosquitoes were collected in the summer of 2015 over 216 trap nights, consisting of 757 Ae. taeniorhynchus and 254 Cx. quinquefasciatus. We collected 38 male and 719 female Ae. taeniorhynchus (Table 1) and 26 male and 228 female Cx. quinquefasciatus (Table 2). Female Ae. taeniorhynchus were captured at all but four sites on Santa Cruz. Abundances of female Ae. taeniorhynchus were highest in coastal elevations and generally declined with increasing elevation; $40 \%$ of female mosquitoes were captured in Puerto Ayora (site 9A and 9B), $14 \%$ at site $3 \mathrm{~A}$, a site $15 \mathrm{~km}$ south of Itabaca Channel, $12 \%$ at Itabaca Channel and $14 \%$ at Miramar (site $8 \mathrm{~A}$ and 8B) (Table 1). In contrast, Cx. quinquefasciatus female mosquitoes were captured at only 8 sites on Santa Cruz

Table 1 Summary of wild-caught totals of Aedes taeniorhynchus with engorged females and resolved blood meals identified across 18 sites on Isla Santa Cruz, Galápagos

\begin{tabular}{|c|c|c|c|c|}
\hline Site & $\begin{array}{l}\text { Total male } \\
\text { captured }\end{array}$ & $\begin{array}{l}\text { Total female } \\
\text { captured }\end{array}$ & $\begin{array}{l}\text { Total blood-fed } \\
\text { mosquitoes }\end{array}$ & $\begin{array}{l}\text { Total } \\
\text { resolved } \\
\text { blood meals }\end{array}$ \\
\hline $1 \mathrm{~A}$ & 0 & 23 & 0 & 0 \\
\hline $1 \mathrm{~B}$ & 2 & 71 & 33 & 31 \\
\hline $2 \mathrm{~A}$ & 0 & 0 & 0 & 0 \\
\hline $2 \mathrm{~B}$ & 0 & 1 & 0 & 0 \\
\hline $3 A$ & 5 & 105 & 44 & 41 \\
\hline $3 B$ & 0 & 0 & 0 & 0 \\
\hline $4 \mathrm{~A}$ & 0 & 0 & 0 & 0 \\
\hline $4 B$ & 0 & 0 & 0 & 0 \\
\hline $5 \mathrm{~A}$ & 2 & 18 & 4 & 4 \\
\hline $5 B$ & 0 & 5 & 0 & 0 \\
\hline $6 \mathrm{~A}$ & 0 & 21 & 18 & 18 \\
\hline $6 \mathrm{~B}$ & 1 & 47 & 23 & 22 \\
\hline $7 \mathrm{~A}$ & 0 & 4 & 0 & 0 \\
\hline $7 B$ & 0 & 4 & 0 & 0 \\
\hline $8 \mathrm{~A}$ & 2 & 2 & 0 & 0 \\
\hline $8 B$ & 1 & 109 & 21 & 20 \\
\hline $9 \mathrm{~A}$ & 3 & 202 & 55 & 52 \\
\hline $9 B$ & 22 & 107 & 47 & 44 \\
\hline Total & 38 & 719 & 245 & 232 \\
\hline
\end{tabular}


Table 2 Summary of wild-caught totals of Culex quinquefasciatus with engorged females and resolved blood meals identified across 18 sites on Isla Santa Cruz, Galápagos

\begin{tabular}{lllll}
\hline Site & $\begin{array}{l}\text { Total male } \\
\text { captured }\end{array}$ & $\begin{array}{l}\text { Total female } \\
\text { captured }\end{array}$ & $\begin{array}{l}\text { Total blood-fed } \\
\text { mosquitoes }\end{array}$ & $\begin{array}{l}\text { Total } \\
\text { resolved } \\
\text { blood meals }\end{array}$ \\
\hline 1A & 0 & 3 & 3 & 2 \\
1B & 4 & 11 & 0 & 0 \\
2A & 0 & 0 & 0 & 0 \\
2B & 0 & 0 & 0 & 0 \\
3A & 5 & 14 & 4 & 4 \\
3B & 0 & 0 & 0 & 0 \\
4A & 0 & 0 & 0 & 0 \\
4B & 0 & 0 & 0 & 0 \\
5A & 0 & 1 & 0 & 0 \\
5B & 0 & 0 & 0 & 0 \\
6A & 0 & 0 & 0 & 0 \\
6B & 0 & 5 & 2 & 2 \\
7A & 0 & 0 & 0 & 0 \\
7B & 0 & 0 & 0 & 0 \\
8A & 0 & 0 & 0 & 0 \\
8B & 0 & 41 & 2 & 1 \\
9A & 12 & 52 & 15 & 46 \\
9B & 5 & 101 & 49 & 69 \\
Total & 26 & 228 & 75 & 14 \\
\hline
\end{tabular}

with $60 \%$ of captures occurring in Puerto Ayora (site 9A and $9 \mathrm{~B}), 16 \%$ at site $8 \mathrm{~B}$ at Miramar and $6 \%$ at Itabaca Channel (site 1A and 1B) and at site 3A (Table 2).

\section{Blood-meal analysis}

Out of 719 female Ae. taeniorhynchus mosquitoes, molecular screening identified 245 females as positive for taking a blood meal from a vertebrate host. Of these, 232 Ae. taeniorhynchus blood meals were resolved with sequencing chromatograms showing single high-quality peaks at each position. Thirteen blood meal sources remained unresolved and either failed to amplify even after multiple PCR attempts (Table 1). We identified 95\% (220 mosquitoes) of blood meal sources as originating from humans (Homo sapiens), 2\% (5 mosquitoes) from cattle (Bos taurus) and 1.7\% (4 mosquitoes) from Galápagos tortoises (Chelonoidis spp.) (Fig. 2). A blood meal from one mosquito captured at site $6 \mathrm{~B}$ in Santa Rosa (381 masl) contained DNA from a bird belonging to the family Hirundinidae and a $100 \%$ match to Tachycineta bicolor. Another Ae. taeniorhynchus mosquito captured at site $1 \mathrm{~B}$ on Itabaca Channel was identified as having taken a blood meal from a reptile (Class Reptilia, Order Squamata). A blood meal from one Ae. taeniorhynchus mosquito captured at site $1 \mathrm{~B}$ on Itabaca Channel was identified as having fed from a mammal in the order Chiroptera (bats) (Fig. 2). Humans were detected as a source of blood meal in mosquitoes captured both in southern and northern Santa Cruz and at low and high elevations. The largest number of mammalian blood meals, including 91 mosquitoes detected with human blood meals, was recorded at Puerto Ayora (site 9A and 9B), populated with nearly 12,000 human inhabitants. Mosquitoes with humans as a source of blood meal were captured at elevations of $\sim 300$ masl and at the highest elevation site in Los Gemelos (site 5A, 618 masl). Cattle (Bos taurus) as a source of blood meals were identified in 4 mosquitoes captured in Santa Rosa (site 6A and 6B) and in one mosquito captured at site 9B in Puerto Ayora. All mosquitoes identified with blood meals from Galápagos tortoises (Chelonoidis spp.) were captured at site 9B in Puerto Ayora (Fig. 2); there is a captive breeding program for tortoises at the Galápagos National Park headquarters located just outside of Puerto Ayora.

For a total of 228 female Cx. quinquefasciatus mosquitoes captured, molecular screening identified 75 mosquitoes with blood meals. Of these, 69 mosquitoes had blood meals that were resolved with chromatograms showing single high-quality peaks, indicating a single source of blood meal from a vertebrate species (Table 2). A total of 68 out of 69 of these blood meals were identified as human with $87 \%(n=60)$ of blood-fed mosquitoes captured in Puerto Ayora (site 9A and 9B) alone (Fig. 3). We identified a single human-fed Culex mosquito at site $8 \mathrm{~B}$ in Miramar, located $5 \mathrm{~km}$ north of Puerto Ayora and at site $6 \mathrm{~B}$, located at Santa Rosa. Mosquitoes identified with human blood meals were also captured at northern sites $3 \mathrm{~A}$ and at the most northern site of Itabaca Channel (site 1A). One mosquito captured at site 6B was identified as positive for having a blood meal from a bird belonging to the family Hirundinidae with a $100 \%$ match to Tachycineta bicolor.

\section{Discussion}

Our analysis of the blood-feeding behavior of mosquitoes gives insight into their roles as disease-carrying vectors on an inhabited island in Galápagos. We found that both Ae. taeniorhynchus and Cx. quinquefasciatus are widespread and that sites with the highest abundances of blood-fed female mosquitoes are those that record high mosquito abundances in general. The number of blood meals from Ae. taeniorhynchus was three times that of $C x$. quinquefasciatus and this corresponded to the sample size of female mosquitoes of each species collected in the summer of 2015. Since we sampled in the dry season of 2015, it is not surprising that we generally captured low numbers of $C x$. quinquefasciatus, a species whose females require freshwater to oviposit eggs. Most $C x$. 


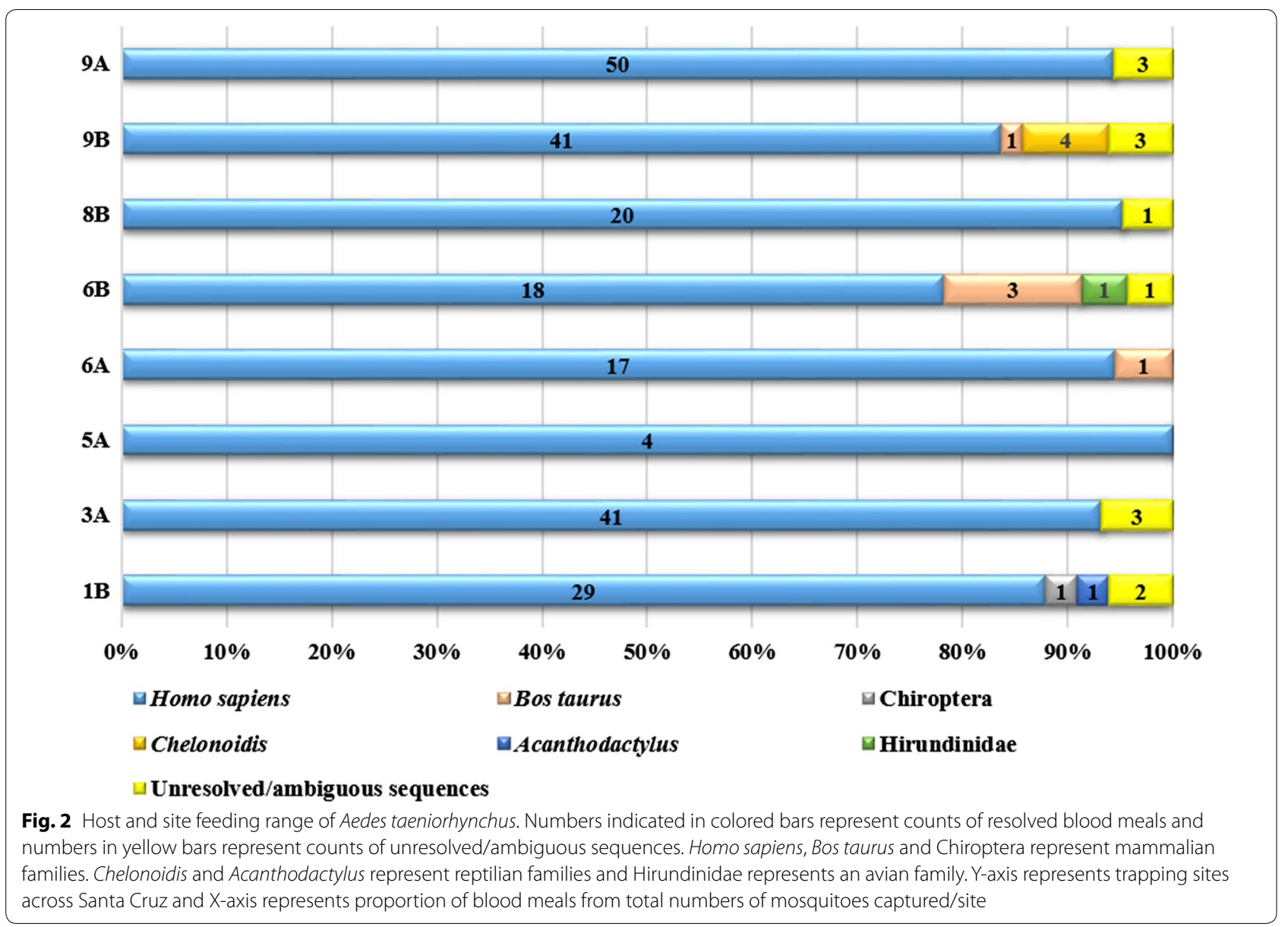

quinquefasciatus mosquitoes were captured in areas of human settlements and this is not surprising given it is a freshwater obligate [36]. Culex mosquitoes have often been associated with human populations who provide conducive environments for mosquito larval development via stagnant rainwater in old tires, ditches, drains, tanks, or containers [37]. On the other hand, since $A e$. taeniorhynchus females oviposit in brackish water, their relatively high abundances in our study could be attributed to the availability of mangrove habitats as well as ideal environmental conditions conducive for mosquito breeding [38]. In general, the abundances and distributional patterns of both mosquito species follow similar patterns to previous studies in Galápagos and can influence disease transmission dynamics amongst native avifauna $[13,15,38,39]$.

Aedes taeniorhynchus has been shown to feed primarily on mammals and reptiles in Galápagos [12]. Our study supports this finding with $99 \%$ of blood meals identified from mammalian and reptilian hosts and included humans, bats, cattle, land tortoises and lava lizards. The only non-reptilian/non-mammalian blood meal was identified as Tachycineta bicolor (tree swallow) which could be a vagrant in Galápagos. The mosquito blood meal could also be from other birds in the family Hirundinidae such as the endemic Galápagos martin (Progne modesta), which is found in the highlands of the central and southern islands of the archipelago or the purple martin (Progne subis), an infrequent visitor.

Mammalian blood meals were highest in our study with $96 \%$ of engorged Aedes females identified as having fed from mammals. Bataille et al. [12] also found that Ae. taeniorhynchus mosquitoes in Galápagos prefer mammals and reptiles over birds. Unfortunately, results from our research cannot support Ae. taeniorhynchus as having a preference due to the study's limitations in lacking data on host abundance and mosquito preference. However, since mammal blood meals were found across the island of Santa Cruz, this can indicate that Ae. taeniorhynchus feeding behavior on mammals is widespread. In areas with human settlements such as in Puerto Ayora, Miramar and Santa Rosa, numbers of engorged mosquitoes were highest, indicating humans as an important source of blood meals for mosquitoes. We also found 


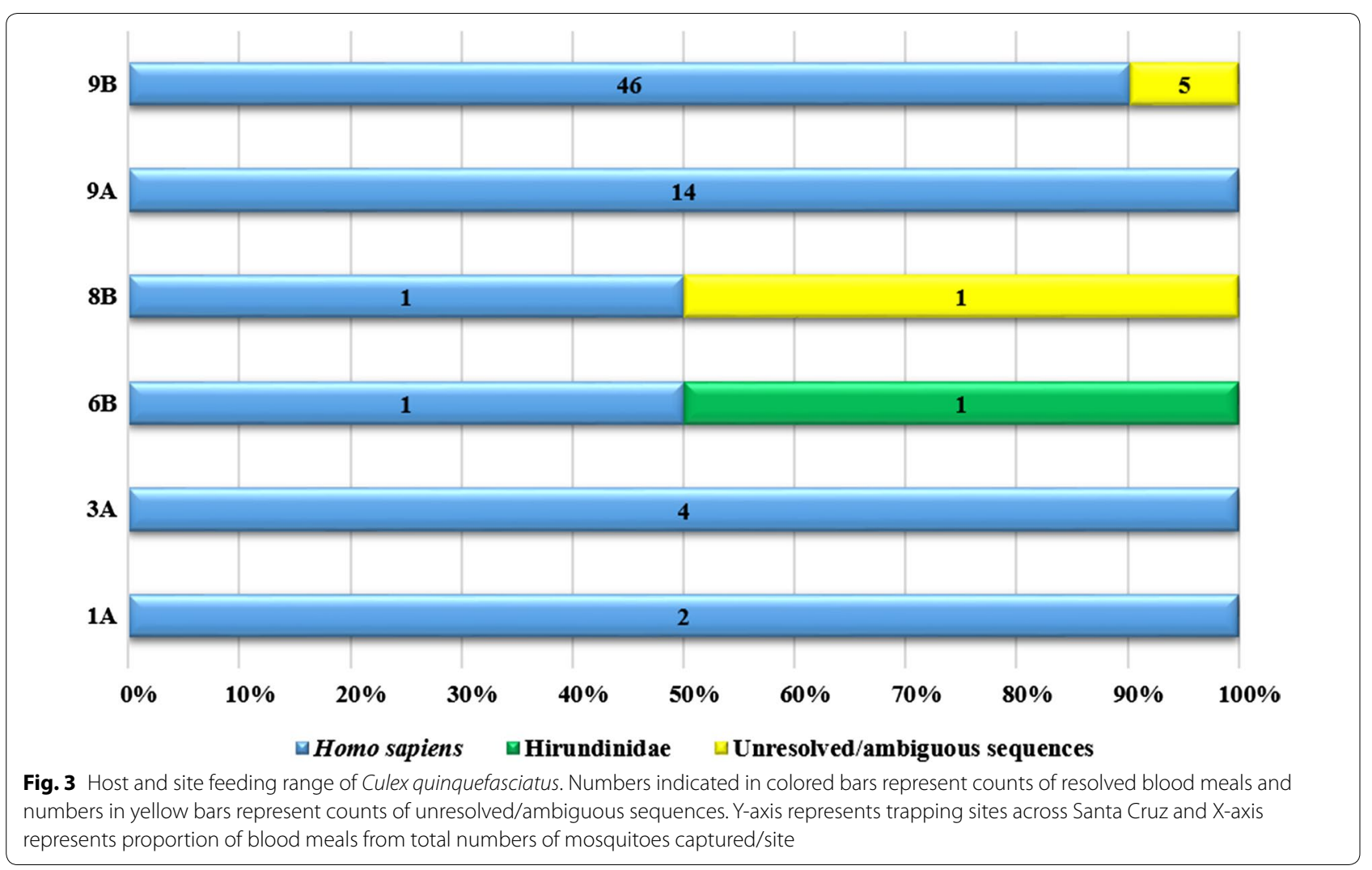

a high proportion of human blood meals in mosquitoes captured at Itabaca Channel, which is the point of entrance for tourists or visitors to Santa Cruz and Galápagos. Both Ae. taeniorhynchus and Cx. quinquefasciatus feed primarily at night and our night-time trapping protocol allowed us to sample when humans were less active and mosquito blood-feeding behaviors were highest. The majority of blood meals in our study originated from humans, whose abundance we did not assess at our capture sites; therefore, we did not include any analysis of preference. However, we do recommend that future sampling of mosquitoes and vertebrate hosts be conducted during diurnal periods as well to better quantify host abundance and determine mosquito preference by use of the foraging ratio analysis [40], which estimates the significance of host blood meal preference as a function of the relative abundance of different host species. In addition, we recommend a systematic sampling of mosquitoes and hosts in uninhabited islands to gain a better understanding of mosquito feeding preferences in and across the Galápagos archipelago.

We also captured blood-fed Ae. taeniorhynchus and $C x$. quinquefasciatus at uninhabited sites, Los Gemelos (site $5 \mathrm{~A}$ ) and site $3 \mathrm{~A}$, suggesting dispersal or movement of mosquitoes throughout the island of Santa Cruz. Mosquitoes have been known to disperse between and within islands in Galápagos through human-aided transportation such as airplanes and boats [41] and the availability of a well-developed road network in Santa Cruz could further facilitate the movement of mosquitoes. Aedes taeniorhynchus is known to disperse up to $40 \mathrm{~km} \mathrm{[42]} \mathrm{while}$ $C x$. quinquefasciatus can travel up to $3 \mathrm{~km}$ [43-45] and their long-range dispersal could further broaden the geographical range of wildlife pathogens.

Adult female Ae. taeniorhynchus feed primarily at night and are hematophagous (or blood-feeders), while males may nectar-feed [46]. Female mosquitoes utilize blood from vertebrate species to develop their eggs; however, this species is partially autogenous, meaning that it can oviposit an initial batch of eggs without a blood meal [47]. Even though a blood meal is not a pre-requisite for egg production in Ae. taeniorhynchus, autogenous females readily consume a blood meal during the first and second day following emergence and blood-feeding can significantly increase egg production [48]. Abundant vertebrate species such as mammals and reptiles in Galápagos provide a readily available foraging resource for partially autogenous Ae. taeniorhynchus females in producing a large initial egg batch, which leads to high mosquito abundances for this species. Hence, if the relatively large non-avian host population contributes to overall egg production and mosquito abundances, disease 
transmission may generally be amplified by mosquitoes, particularly if they are competent arthropod vectors. This amongst many factors such as infection rate, availability of sites for the development of mosquito larvae and abiotic factors such as rainfall and temperature would result in a greater risk of disease transmission of parasites such as avian malaria to native birds, compared to what would be expected in areas of low mammalian and reptilian host abundances.

Examination of blood-fed mosquitoes in our study showed an almost exclusively mammalian diet of $C x$. quinquefasciatus on Santa Cruz. With the exception of one blood meal from a bird belonging to the family Hirundinidae, all analyzed blood meals were identified as human. Our study may support research that indicates that $C x$. quinquefasciatus is an inherent opportunistic feeder [49] and a generalist feeder, meaning that it feeds indiscriminately on both birds and mammals [50]. However, our results need to be interpreted with caution given the absence of a foraging ratio analysis. Our findings may also indicate humans as one of the most abundant host species that is locally available, but this does not necessarily mean that it is the preferred host. For instance, blood meal screening from $C x$. quinquefasciatus captured in Kenya revealed only 3-9.8\% of human blood meals; the majority of blood meals originated from other mammals such as cattle, goats and donkeys [51]. In Tanzania, experimentation with an equal availability of three vertebrate species found $C x$. quinquefasciatus behavior as highly anthropophilic [52]. In other sites, $C x$. quinquefasciatus has also been shown to generally prefer feeding on birds [50] and occasionally on reptiles, amphibians, and mammals [53, 54]. In northeastern Mexico, foraging ratios of $C x$. quinquefasciatus were highest for chickens compared to humans, horses and pigs and this was attributed to chickens being highly abundant in the area of study [55]. Sites included in our trapping scheme which fall in agricultural zones include Bellavista and Santa Rosa, both located on southern slopes of Isla Santa Cruz. During trapping nights at both locations, our mosquito traps were placed closer to human settlements than to agricultural sites and therefore could have resulted in the greater detection of human blood meals than from farm animals such as chickens, pigs and cows at nearby farms. Nevertheless, the high plasticity in feeding behavior in $C x$. quinquefasciatus could indicate that it may be an opportunistic feeder as referenced in many studies above and that its feeding behavior varies with locally available and abundant species. However, without a proper estimation of host abundances and feeding preferences of mosquitoes in Galápagos, caution must be applied, as the findings from other mosquito blood meal studies might not be transferable to mosquitoes in our study area. In addition, realizing that our research lacks an abundance estimate of different fauna to be utilized in a foraging ratio analysis, we cannot say with confidence that any particular species is highly abundant or is preferred as a blood meal source by mosquitoes in Santa Cruz.

Nevertheless, even though mammals made significant contributions to the blood meals of $C x$. quinquefasciatus and Ae. taeniorhynchus, both mosquitoes also fed on other non-mammalian vertebrate species. The plasticity of mosquitoes in Galápagos to feed on different vertebrate blood meal sources could give us clues to the transmission of wildlife pathogens among hosts. For instance, if mosquitoes feed broadly on a range of nonavian host species, the chance of detecting avian parasites is small. The avian malaria parasite (Plasmodium spp.) has a very low infection rate in Galápagos and may be difficult to detect, particularly if competent vectors such as $C x$. quinquefasciatus are not abundant and are feeding mostly on non-avian hosts such as mammals and reptiles. In fact, Culex mosquitoes have been shown to modify their feeding preferences based on host availability and abundance and provide a bridge in the transmission of West Nile virus (WNV) from birds to humans [34, 35]. A detailed study integrating feeding behavior of mosquitoes and composition of host species showed that American robins, which are competent WNV hosts, were preferentially fed on by the mosquito species Culex tarsalis. However, during periods of robin dispersal and migration, $C x$. tarsalis shifted its feeding preferences from birds to humans. This greatly amplified the number of human infections, particularly when mosquito infection prevalence was high from feeding on infected robins [56]. Culex quinquefasciatus has the capacity to transmit avian malaria [1] but the low malarial infection rate and generalist feeding behavior of Culex could be minimizing the chances of detecting Plasmodium in Galápagos mosquito sampling. Additional studies investigating the feeding preferences of mosquitoes on islands without human populations along with experimental infection of hosts and arthropod vectors are recommended to resolve this question.

\section{Conclusions}

Our study assessed the feeding patterns of two common mosquito species, Ae. taeniorhynchus and $C x$. quinquefasciatus in the inhabited island of Santa Cruz, Galápagos. Our results indicated a high proportion of mammalian blood meals in both species, which may reflect locally available and abundant hosts in Santa Cruz. However, surveys documenting the relative abundances of hosts as potential sources of mosquito blood meals will need to accompany mosquito trapping studies to further 
validate this. Determining the host feeding range of mosquitoes and their feeding preferences is critical to understanding the disease dynamics of wildlife pathogens such as avian malaria. This knowledge is important in contributing towards managing pathogens that threaten the conservation of endemic wildlife, particularly avifauna in isolated islands such as Galápagos.

\begin{abstract}
Abbreviations
BM: blood meal; CA: California; CDC: Centers for Disease Control, USA; CDF: Charles Darwin Foundation; dNTP: deoxyribonucleotide triphosphate; FRC: Field Research for Conservation Program, Saint Louis Zoo; GNP: Galápagos National Park; IUCN: International Union for Conservation of Nature; KCl: potassium chloride; masl: meters above sea level; $\mathrm{MgCl}_{2}$ : magnesium chloride; PCR: polymerase chain reaction; Tris-HCl: Tris (hydroxymethyl) aminomethane hydrochloride; USDA APHIS: United States Department of Agriculture-Animal and Plant Inspection Service; UMSL: University of Missouri Saint Louis; WNV: West Nile virus.
\end{abstract}

\section{Acknowledgements}

This research would not be possible without the support of the Whitney $R$ Harris World Ecology Center, the Saint Louis Zoo Field Research for Conservation (FRC) program and the Des Lee Fund for Zoological Studies. We thank the Charles Darwin Foundation (CDF) for providing logistical assistance and the Galápagos National Park (GNP) for facilitating research permits. Both CDF and GNP assisted in exporting our samples in a timely manner and provided tremendous assistance during the sampling period. A sincere gratitude to the Galápagos National Park especially Alonso Carrion and the Park Rangers Roberto Jimenez, Wilson Cabrera, Jean Pierre Cadena, José Villafuerte, Simon Villamar and Tito Mendoza who assisted in the collection of the samples and made the field research possible. We thank the people of Galápagos who offered rides to and from field sites. We also thank Drs. Steven Juliano, Robert Marquis and Nathan Muchhala for providing critical feedback in shaping the design of this research. We also appreciate the laboratory assistance of Cindee Rettke, Lisa Rois, Nathan Jones, Ben Nguyễn, May Allgire and Jose Antonio Iturrizaga Shaw. Finally, but not the least, we thank the Parker laboratory at the University of Missouri Saint Louis for providing constructive feedback, edits and revisions during earlier versions of this manuscript. This publication is contribution number 2265 of the Charles Darwin Foundation for the Galápagos Islands.

\section{Authors' contributions}

SA and PGP contributed to the hypotheses design and design of the field and laboratory methodology. SA collected all field data, dissected mosquitoes, optimized PCR conditions and primers for mosquito blood meal screening, analyzed and interpreted data and wrote the original manuscript. SS contributed to the optimization of PCR conditions and primers used for mosquito blood meal screening and assessed sequence chromatograms for analysis. PGP contributed to funding research both in the field and laboratory, provided guidance for the optimization of primers and PCR conditions, interpreted data and provided critical commentary to several earlier drafts of this manuscript. All authors read and approved the final manuscript.

\section{Funding}

This project was conducted as part of the UMSL Des Lee Fund for Zoological Studies granted to PGP (Grant No DesLeeFund_Parker). The project was also funded by the Whitney R Harris World Ecology Center (Grant No WRHWEC Salah). We also received funding from the Saint Louis Zoo Field Research for Conservation (FRC) (Grant No FRC \# 13-01) and Des Lee Fund for Zoological Studies.

\section{Availability of data and materials}

Data supporting the conclusions of this article are included within the article.

\section{Ethics approval and consent to participate}

All samples were collected with the permission of the Galápagos National Park under permit number: PC-37-13 and imported to the USA in compliance with permits from the USA Fish and Wildlife Service under license: USDA APHIS 47418. All mosquito specimens collected were neither endangered or listed as a protected species under the IUCN, International Union for Conservation of Nature Red List of Threatened Species.

\section{Consent for publication}

Not applicable.

\section{Competing interests}

The authors declare that they have no competing interests.

\section{Author details}

${ }_{1}^{1}$ Department of Biology, University of Missouri, St. Louis, One University Blvd., St. Louis, MO 63121, USA. ${ }^{2}$ Whitney R. Harris World Ecology Center, University of Missouri, One University Blvd., St. Louis, MO 63121, USA. ${ }^{3}$ WildCare Institute, Saint Louis Zoo, One Government Drive, St. Louis, MO 63110, USA.

Received: 8 May 2019 Accepted: 3 December 2019

Published online: 16 December 2019

\section{References}

1. van Riper C, van Riper SG, Goff ML, Laird M. The epizootiology and ecological significance of malaria in Hawaiian land birds. Ecol Monogr. 1986;56:327-44.

2. Bhatt S, Gething PW, Brady OJ, Messina JP, Farlow AW, Moyes CL, et al. The global distribution and burden of dengue. Nature. 2013;496:504-7.

3. Greenwood BM, Bojang K, Whitty CJM, Targett GAT. Malaria. Lancet 2014;365:1487-98.

4. Gillies MT. Selection for host preference in Anopheles gambiae. Nature. 1964;203:852-4.

5. Ulloa A, Arredondo Jimenez II, Rodriguez MH, Fernandez Salas I, Gonzalez Ceron L, Arredondo-Jimenez Jl, et al. Innate host selection in Anopheles vestitipennis from southern Mexico. J Am Mosq Control Assoc. 2004;20:337-41.

6. Thiemann TC, Wheeler SS, Barker CM, Reisen WK. Mosquito host selection varies seasonally with host availability and mosquito density. PLoS Negl Trop Dis. 2011;5:e1452.

7. Simpson JE, Hurtado PJ, Medlock J, Molaei G, Andreadis TG, Galvani AP, et al. Vector host-feeding preferences drive transmission of multi-host pathogens: West Nile virus as a model system. Proc R Soc B Biol Sci. 2012;279:925-33.

8. Atkinson CT, LaPointe DA. Ecology and pathogenicity of avian Malaria and Pox. In: Pratt Thane K, Atkinson Carter T, Banko Paul C, Jacobi James $D$, Woodworth Bethany $L$, editors. Conservation biology of hawaiian forest birds: implications for Island Avifauna. New Haven: Yale University Press; 2009. p. 234-52.

9. van Riper IIIC, van Riper S, Hansen W, Hackett S. Epizootiology and effect of avian pox on Hawaiian forest birds. Auk. 2002;119:929-42.

10. Darwin C. On the origin of species by means of natural selection, or the preservation of favoured races in the struggle for life. New York: P.F. Collier \& Son; 1859.

11. Bataille A, Cunningham AA, Cedeño V, Patiño L, Constantinou A, Kramer LD, et al. Natural colonization and adaptation of a mosquito species in Galápagos and its implications for disease threats to endemic wildlife. Proc Natl Acad Sci USA. 2009:106:10230-5.

12. Bataille A, Fournié G, Cruz M, Cedeño V, Parker PG, Cunningham AA, et al. Host selection and parasite infection in Aedes taeniorhynchus, endemic disease vector in the Galápagos Islands. Infect Genet Evol. 2012:12:1831-41.

13. Causton CE, Peck SB, Sinclair BJ, Landry B, Peck SB, Sinclair BJ, et al. Alien insects: threats and implications for conservation of Galápagos Islands. Ann Entomol Soc Am. 2006;99:121-43.

14. Whiteman NK, Whiteman NK, Goodman SJ, Sinclair BJ, Walsh T, Cunningham AA, et al. Establishment of the avian disease vector Culex quinquefasciatus Say, 1823 (Diptera: Culicidae) on the Galápagos Islands, Ecuador. Ibis Br Ornithol Union. 2005:147:844-7.

15. Asigau S, Hartman DA, Higashiguchi JM, Parker PG. The distribution of mosquitoes across an altitudinal gradient in the Galápagos Islands. J Vector Ecol. 2017;42:243-53. 
16. Levin II, Zwiers P, Deem SL, Geest EA, Higashiguchi JM, lezhova TA, et al. Multiple lineages of avian malaria parasites (Plasmodium) in the Galápagos Islands and evidence for arrival via migratory birds. Conserv Biol. 2013;27:1366-77.

17. Levin II, Outlaw DC, Vargas FH, Parker PG. Plasmodium blood parasite found in endangered Galápagos penguins (Spheniscus mendiculus). Biol Conserv. 2009:142:3191-5.

18. Levin II, Valkiūnas G, lezhova TA, O'Brien SL, Parker PG. Novel Haemoproteus species (Haemosporida: Haemoproteidae) from the swallow-tailed gull (Lariidae), with remarks on the host range of hippoboscid-transmitted avian hemoproteids. J Parasitol. 2012;98:847-54.

19. Levin II, Valkiu-nas G, Santiago-Alarcon D, Cruz LL, lezhova TA, O'Brien SL, et al. Hippoboscid-transmitted Haemoproteus parasites (Haemosporida) infect Galápagos pelecaniform birds: evidence from molecular and morphological studies, with a description of Haemoproteus iwa. Int J Parasitol. 2011:41:1019-27.

20. Padilla LR, Santiago-Alarcon D, Merkel J, Miller RE, Parker PG. Survey for Haemoproteus spp., Trichomonas gallinae, Chlamydophila psittaci, and Salmonella spp. in Galápagos Islands columbiformes. J Zoo Wildl Med. 2004:35:60-4

21. Santiago-Alarcon D, Whiteman NK, Parker PG, Ricklefs RE, Valkiūnas G. Patterns of parasite abundance and distribution in island populations of Galápagos endemic birds. J Parasitol. 2008;94:584-90.

22. Merkel J, Jones HI, Whiteman NK, Gottdenker N, Vargas H, Travis EK, et al. Microfilariae in Galápagos penguins (Spheniscus mendiculus) and flightless cormorants (Phalacrocorax harrisi): genetics, morphology, and prevalence. J Parasitol. 2007:93:495-503.

23. Parker PG, Buckles EL, Farrington H, Petren K, Whiteman NK, Ricklefs RE, et al. 110 years of Avipoxvirus in the Galápagos Islands. PLoS ONE. 2011;6:e15989.

24. Swash A, Still R. Birds, Mammals, and reptiles of the Galápagos Islands: An identification guide. 2nd ed. New Haven and London: Yale University Press; 2005.

25. INEC. Censo de Población y Vivienda 2010. Quito, Ecuador; 2010. https:// www.ecuadorencifras.gob.ec/censo-de-poblacion-y-vivienda. Accessed 1 Feb 2018.

26. PNG. Informe anual de visitantes que ingresaron a las áreas protegidas de Galápagos 2013. Santa Cruz, Galápagos; 2013. http://www.ambiente.gob. ec. Accessed 10 Mar 2018

27. Smallegange RC, Schmied WH, van Roey KJ, Verhulst NO, Spitzen J, Mukabana WR, et al. Sugar-fermenting yeast as an organic source of carbon dioxide to attract the malaria mosquito Anopheles gambiae. Malar J. 2010;9:292

28. Gillies MT. The role of carbon dioxide in host-finding by mosquitoes (Diptera: Culicidae): a review. Bull Entomol Res. 1980;70:525.

29. Reiter P. A standardized procedure for the quantitative surveillance of certain Culex mosquitoes by egg raft collection. J Am Mosq Control Assoc. 1986;2:219-21.

30. Belkin J. The mosquitoes of the South Pacific (Diptera, Culicidae). Berkely and Los Angeles: University of Carlifonia Press; 1962.

31. Detinova TS. Age-grouping methods in Diptera of medical importance with special reference to some vectors of malaria. Monogr Ser World Health Organ. 1962:47:13-191.

32. Longmire JL, Lewis AK, Brown NC, Buckingham JM, Clark LM, Jones $\mathrm{MD}$, et al. Isolation and molecular characterization of a highly polymorphic centromeric tandem repeat in the family Falconidae. Genomics. 1988:2:14-24.

33. Kocher TD, Thomas WK, Meyer A, Edwards SV, Paabo S, Villablanca FX, et al. Dynamics of mitochondrial DNA evolution in animals: amplification and sequencing with conserved primers. Proc Natl Acad Sci USA. 1989;86:6196-200.

34. Molaei G, Andreadis TG, Armstrong PM, Anderson JF, Vossbrinck CR. Host feeding patterns of Culex mosquitoes and West Nile virus transmission, northeastern United States. Emerg Infect Dis. 2006;12:468-74.

35. Hamer GL, Kitron UD, Goldberg TL, Brawn JD, Loss SR, Ruiz MO, et al. Host selection by Culex pipiens mosquitoes and West Nile virus amplification. Am J Trop Med Hyg. 2009;80:268-78.
36. Patrick ML, Bradley TJ. The physiology of salinity tolerance in larvae of two species of Culex mosquitoes: the role of compatible solutes. J Exp Biol. 2000:203:821-30

37. Teng $H J, W u Y L, L i n T H$. Mosquito fauna in water-holding containers with emphasis on dengue vectors (Diptera: Culicidae) in Chungho, Taipei County, Taiwan. J Med Entomol. 1999;36:468-72.

38. Asigau S, Parker PG. The influence of ecological factors on mosquito abundance and occurrence in Galápagos. J Vector Ecol. 2018;43:125-37.

39. Bataille A, Cunningham AA, Cruz M, Cedeno V, Goodman SJ. Seasonal effects and fine-scale population dynamics of Aedes taeniorhynchus, a major disease vector in the Galápagos Islands. Mol Ecol. 2010;19:4491-504.

40. Kent RJ. Molecular methods for arthropod bloodmeal identification and applications to ecological and vector-borne disease studies. Mol Ecol Resour. 2009;9:4-18.

41. Bataille A, Cunningham AA, Cedeño V, Cruz M, Eastwood G, Fonseca DM, et al. Evidence for regular ongoing introductions of mosquito disease vectors into the Galápagos Islands. Proc Biol Sci. 2009:276:3769-75.

42. Provost MW. The dispersal of Aedes taeniorhynchus. II-the second experiment. Mosq News. 1957:17:233-47.

43. Lapointe DA. Dispersal of Culex quinquefasciatus (Diptera: Culicidae) in a Hawaiian rain forest. J Med Entomol. 2008;45:600-9.

44. Medeiros MCl, Boothe EC, Roark EB, Hamer GL. Dispersal of male and female Culex quinquefasciatus and Aedes albopictus mosquitoes using stable isotope enrichment. PLoS Negl Trop Dis. 2017;11:e0005347.

45. Reisen WK, Milby MM, Meyer RP, Pfuntner AR, Spoehel J, Hazelrigg JE, et al. Mark-release-recapture studies with Culex mosquitoes (Diptera: Culicidae) in southern California. J Med Entomol. 1991;28:357-71.

46. Burkett-Cadena ND. Mosquitoes of the southeastern United States. Tuscaloosa: The University of Alabama Press; 2013.

47. Lea AO, Lum PTM. Autogeny in Aedes taeniorhynchus (Wied.). J Econ Entomol. 1959;52:356-7.

48. O'Meara GF, Evans DG. Blood-feeding requirements of the mosquito: geographical variation in Aedes taeniorhynchus. Science. 1973;180:1291-3.

49. Takken W, Verhulst NO. Host preferences of blood-feeding mosquitoes. Annu Rev Entomol. 2013;58:433-53.

50. Zinser M, Ramberg F, Willott E. Culex quinquefasciatus (Diptera: Culicidae) as a potential West Nile virus vector in Tucson, Arizona: blood meal analysis indicates feeding on both humans and birds. J Insect Sci. 2004;4:20.

51. Muturi EJ, Muriu S, Shililu J, Mwangangi JM, Jacob BG, Mbogo C, et al. Blood-feeding patterns of Culex quinquefasciatus and other culicines and implications for disease transmission in Mwea rice scheme, Kenya. Parasitol Res. 2008;102:1329-35.

52. Mboera LEG, Takken W. Odour-mediated host preference of Culex quinquefasciatus in Tanzania. Entomol Exp Appl. 1999;92:83-8.

53. Janssen N, Fernandez-Salas I, Díaz González EE, Gaytan-Burns A, Medina-de la Garza CE, Sanchez-Casas RM, et al. Mammalophilic feeding behaviour of Culex quinquefasciatus mosquitoes collected in the cities of Chetumal and Cancun, Yucatán Peninsula. Mexico. Trop Med Int Heal. 2015;20:1488-91.

54. Farajollahi A, Fonseca DM, Kramer LD, Marm Kilpatrick A. "Bird biting" mosquitoes and human disease: A review of the role of Culex pipiens complex mosquitoes in epidemiology. Infect Genet Evol. 2011;11:1577-85.

55. Elizondo-Quiroga A, Flores-Suarez A, Elizondo-Quiroga D, Ponce-Garcia G, Blitvich BJ, Contreras-Cordero JF, et al. Host-feeding preference of Culex quinquefasciatus in Monterrey, northeastern Mexico. J Am Mosquito Control. 2006;22:654-61.

56. Kilpatrick AM, Kramer LD, Jones MJ, Marra PP, Daszak P. West Nile virus epidemics in North America are driven by shifts in mosquito feeding behavior. PLoS Biol. 2006:4:606-10.

\section{Publisher's Note}

Springer Nature remains neutral with regard to jurisdictional claims in published maps and institutional affiliations. 